\title{
Influence of Clastic Dikes on Vertical Migration of Contaminants in the Vadose Zone at Hanford
}

(Project Number: 70193)

\section{Principal Investigator}

Christopher J. Murray

Pacific Northwest National Laboratory

P.O. Box 999, MSIN K6-81

Richland, WA 99352

(509) 376-5848 (phone)

Chris.Murray@pnl.gov

\section{Co-Investigators}

John L. Wilson

Department of Earth and Environmental Science

New Mexico Institute of Mining and Technology

Socorro, NM 87801

(505) 835-5308 (phone)

jwilson@nmt.edu

Michael J. Fayer

Pacific Northwest National Laboratory

P.O. Box 999, MSIN K9-33

Richland, WA 99352

(509) 372-6045 (phone)

mike.fayer@pnl.gov

\section{Graduate Students}

Benjamin Lechler, M.S.

Zachary Brown, M.S. 


\section{Research Objective}

This research project addresses the effect of clastic dikes on contaminant transport in the vadose zone. Clastic dikes are vertically oriented subsurface heterogeneities that are common at the Hanford Site, including the subsurface sediments below the tank farms in the 200 West Area. Previous studies have suggested that clastic dikes may provide a fast path for transport of leaking fluid from the tanks through the vadose zone.

This research will test the hypothesis that clastic dikes at the Hanford Site provide preferential pathways that enhance the vertical movement of moisture and contaminants through the vadose zone. Current flow and transport models of the vadose zone at the 200 Areas are based on relatively simple hydrogeologic models that assume horizontally layered sediments with no preferential vertical flow paths. To address those scientific needs, our research includes field and modeling studies of the spatial distribution of clastic dikes, the hydrologic properties within dikes, and the potential effect of clastic injection dikes on fluid flow through the vadose zone. The data and models of the clastic dike networks produced for this project should be directly applicable to fate and transport studies conducted at the 200 West Hanford tank farms.

\section{Research Progress and Implications}

This report summarizes progress after the first 20 months of a 3-year project. In 2000, the project used remote sensing and ground-penetrating radar surveys to describe the large-scale distribution of the clastic dikes along Army Loop Road in the 600 Area and at the 216-S-16 pond. Figure 1 shows the dikes at the two sites as mapped into a geographic information system (GIS) from air photographs. We then used the GIS to extract the lengths, area of the polygons, and azimuth of the dikes, and made simple statistical analyses. In addition, we made four field traverses across the dike swarm and measured the widths of dikes crossed during the traverses. The edges of the dikes were interpreted to be the boundaries where the density of vegetation changed (vegetation is thicker on the dikes than on the host soil because the dikes tend to hold more moisture). Figures 2 through 5 show the distribution of the measured properties. The mean length of the dikes is 62 meters, and the average width of the surface expression of the dikes is just over 2 meters. The rose diagram (Figure 5) indicates a slight preferential orientation to the dikes in the network, with many of the dikes occurring in two conjugate sets. Those sets have north, northwest-south, southeast and north, northeast-south, southwest orientations.

We conducted surface ground-penetrating radar surveys at three areas: square grid surveys were conducted at the Army Loop Road site and at the 216-S-16 pond, and measurements were made on a 6.9 kilometer traverse in the 600 Area (see Figure 1). The surveys helped in mapping the dikes and detecting smaller dikes not visible on air photos or the ground surface. In general, the data quality at the 216-S-16 pond was not good because numerous diffractions in the data interfered with deeper reflections. Those diffractions are probably from cobbles and boulders exposed at the surface and buried in the ground. The data quality of the Army Loop Road survey and the 6.9-kilometer traverse were significantly better. Figures 6 and 7 show examples from the 


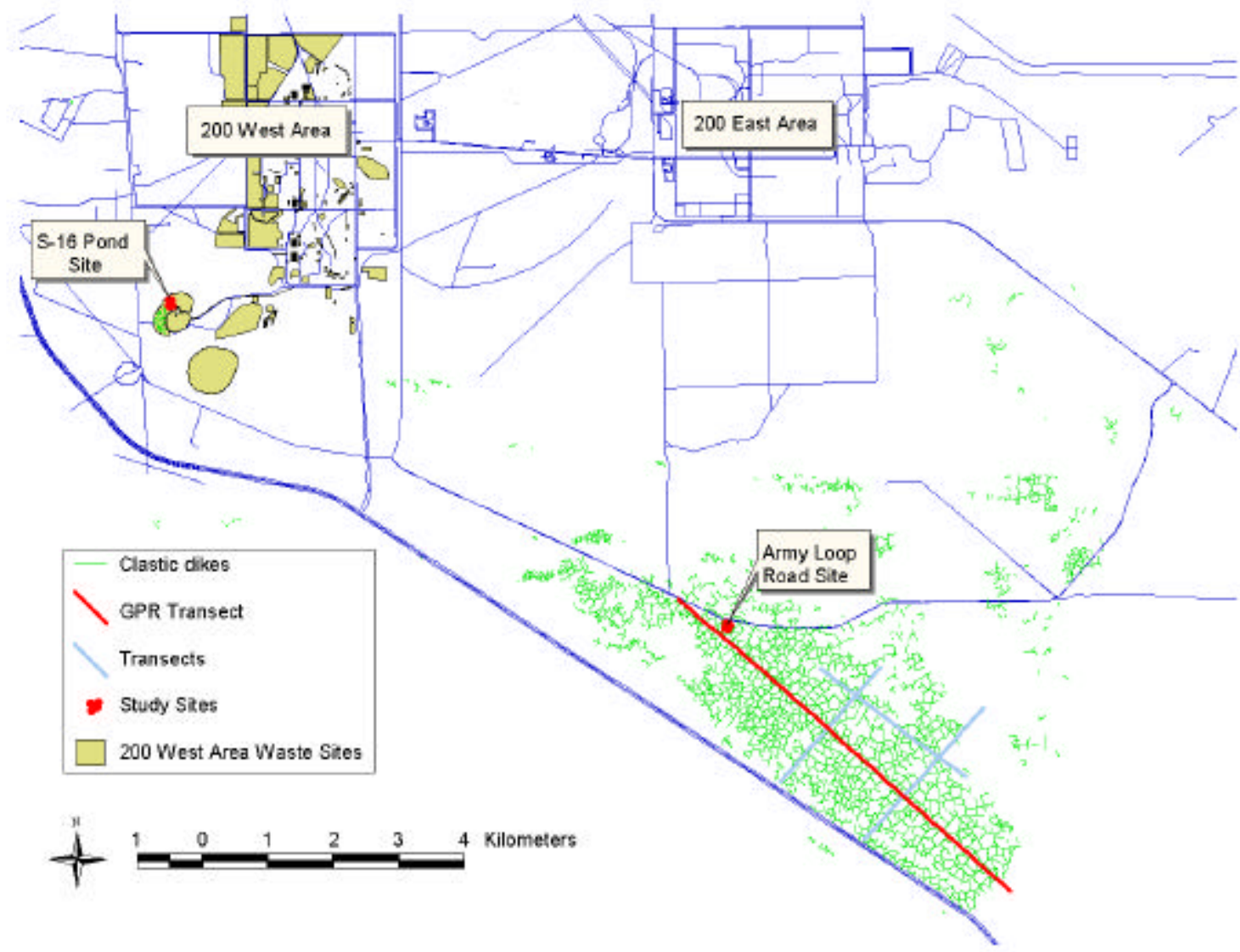

Figure 1. Distribution of Clastic Dikes at the Army Loop Road Site and the 216-S-16 Pond

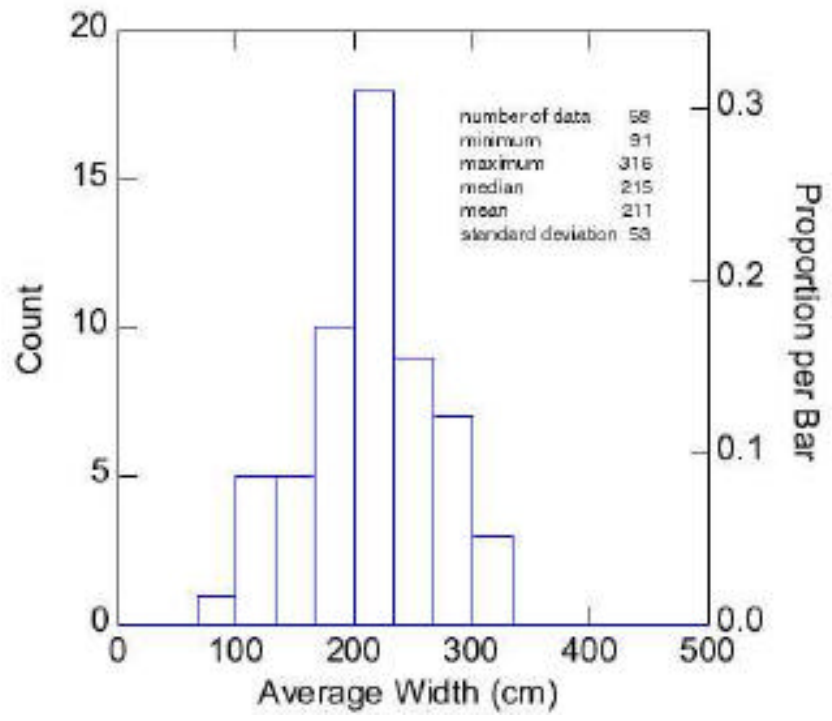

Figure 2. Distribution of Widths of Clastic Dikes at the Army Loop Road Site 


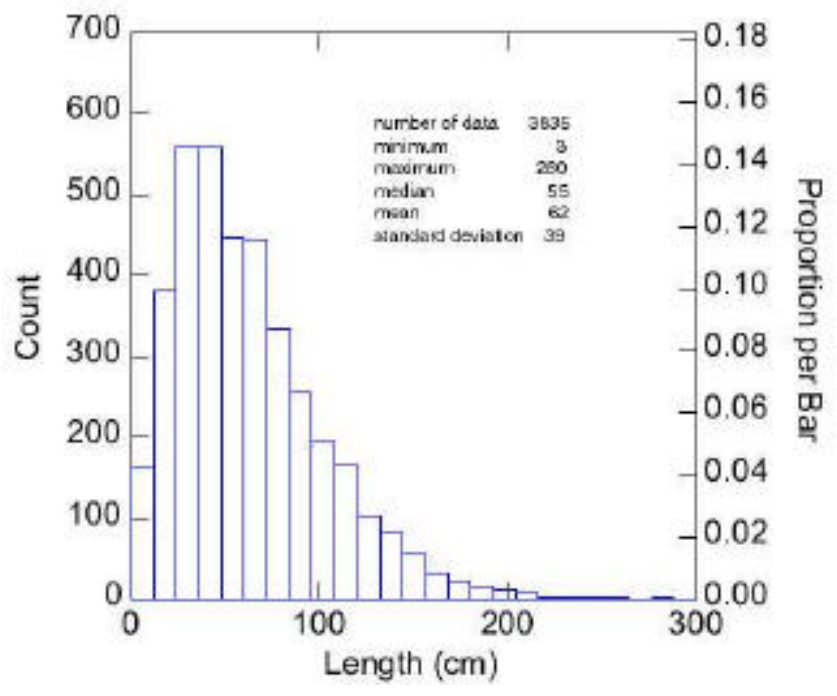

Figure 3. Distribution of Lengths of Clastic Dikes at the Army Loop Road Site

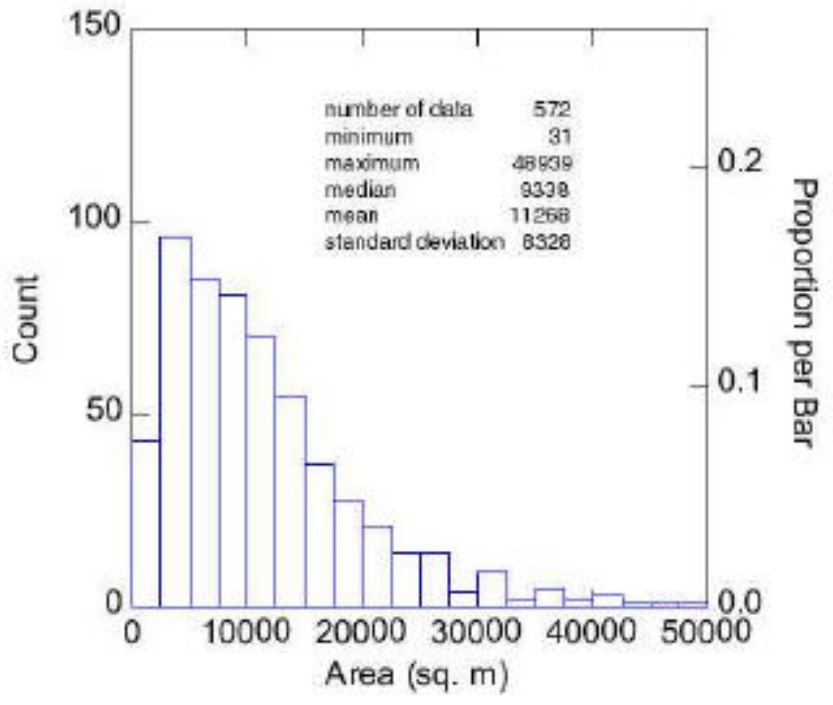

Figure 4. Distribution of Polygon Areas of Clastic Dikes at the Army Loop Road Site 


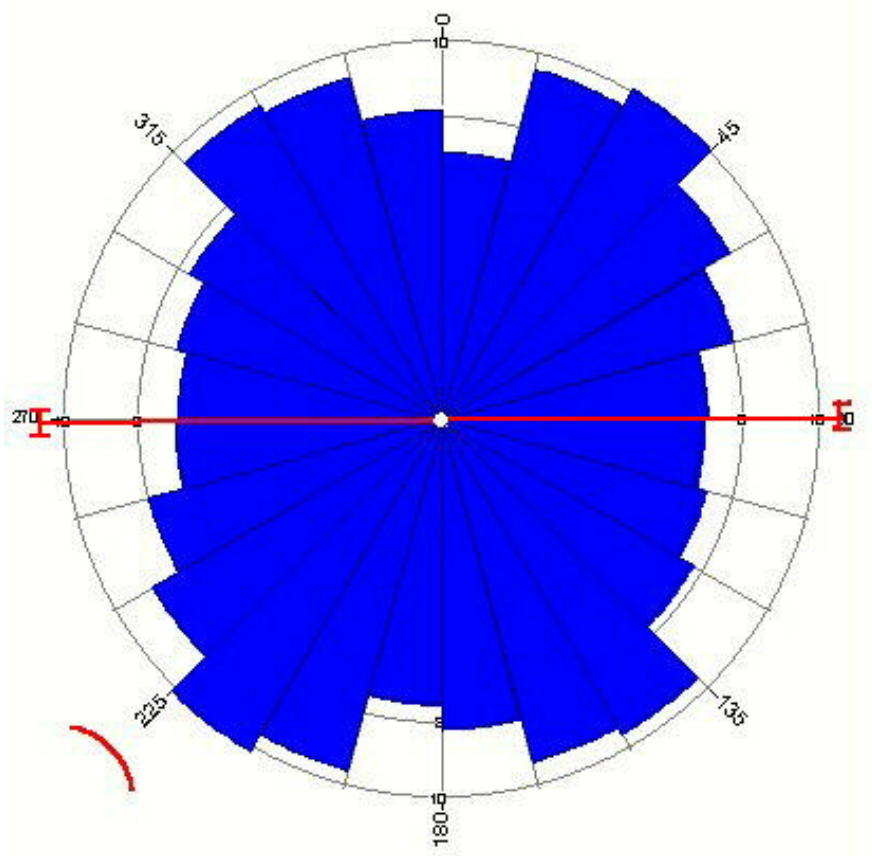

Figure 5. Distribution of Clastic Dike Azimuth at the Army Loop Road Site

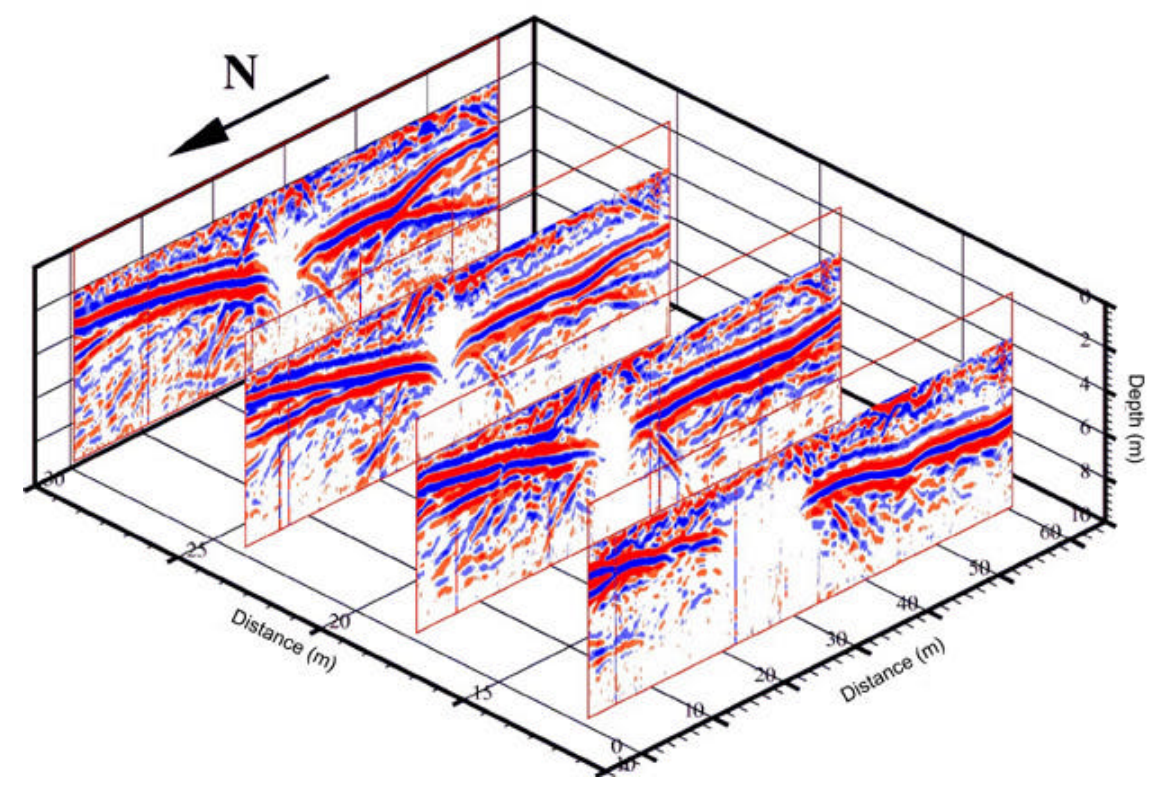

Figure 6. Fence Diagram of the Northeast-Southwest Army Loop Road Profiles 


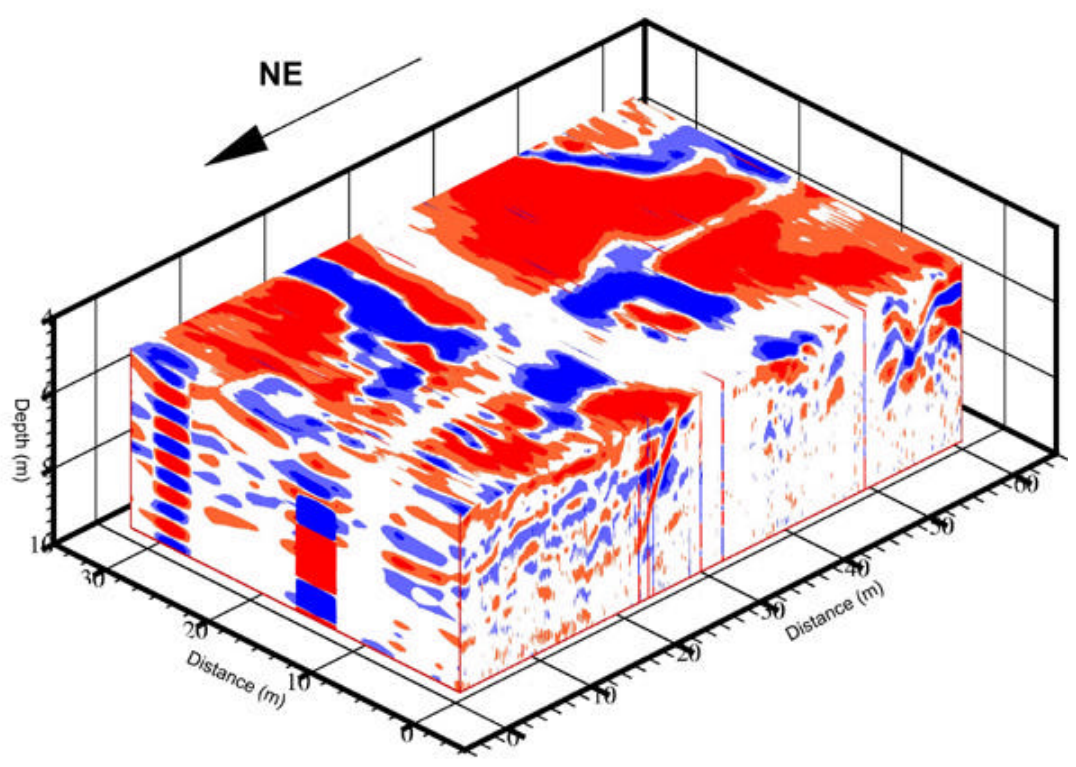

Figure 7. Three-Dimensional Diagram of the Data from the Army Loop Road Survey

ground-penetrating radar survey at Army Loop Road. Figure 6 shows four northeast-southwest profiles. The white area at $\sim 30$ meters distance in the northeast-southwest direction on each traverse is a clastic dike. Figure 7 is a three-dimensional view of the same area. The white area along the plot's surface corresponds to the subsurface expression of a clastic dike. A second dike can be seen at $\sim 10$ meters on the east-west face of the plot. The second dike intersects the first dike near the center of the diagram.

We used the ground-penetrating radar survey and the air photo and field mapping to select a site to trench across a clastic dike. In August 2000, we trenched a clastic dike at the 216-S-16 pond with a backhoe to a depth of $\sim 3.5$ meters (Figure 8 ). The exposed clastic dike is in the sanddominated facies of the Hanford formation. The dike is $\sim 0.7$ meter thick at the bottom of the trench but becomes extremely narrow ( $~ 8$ to 10 centimeters) within $\sim 1$ meter of the surface. The narrow portion of the dike appears to be reactivation of the dike along an older dike surface. In the exposures made by the lower two lifts, the host material is very different on each side of the dike (see Figure 8). The material to the west of the dike (to the left in Figure 8) is medium to coarse-grained laminated sand containing some silt and sand rip-up clasts. The material to the east of the dike consists of finer-grained, silty fine to medium sand. In addition, a clastic sill (a structure similar to a clastic dike but concordant with horizontal bedding) is exposed east of the dike, near the base of the trench. The sill is seen in Figure 8 as the $~ 8$-centimeters-thick, finegrained unit to the right of the dike in the lower part of the trench. The heterogeneities within both the host sediment and within the dike complicate comparison of physical property data from samples of dike and host. The trench was dug in four lifts. After each lift, except the first, the 


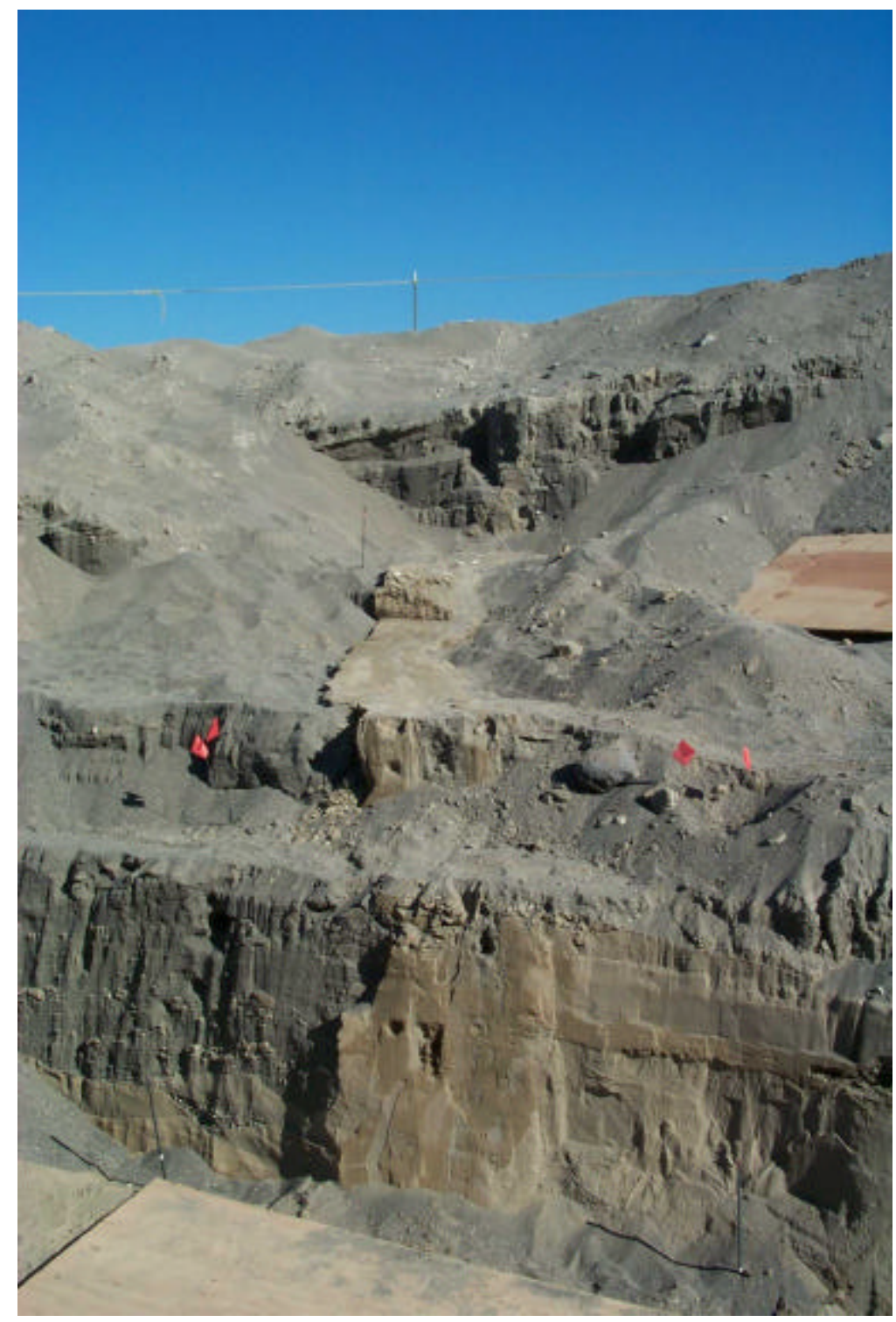

Figure 8. Clastic Dike Exposed in Trench at 216-S-16 Pond

dike and host sediment were characterized by air permeability measurements and infrared imagining. In addition, samples were taken for moisture analyses, grain size distribution, and mineralogy (X-ray diffraction).

Figure 9 shows two composite photographs of the lowest level in the trench. The lower photo is a normal photograph, and the upper photo is infrared. The contrast in the infrared photo is due to variation in the moisture content of the sediment; darker colors indicate more moisture. The dark vertical band on the left side of the infrared photo is the clastic dike, and the dark horizontal band 

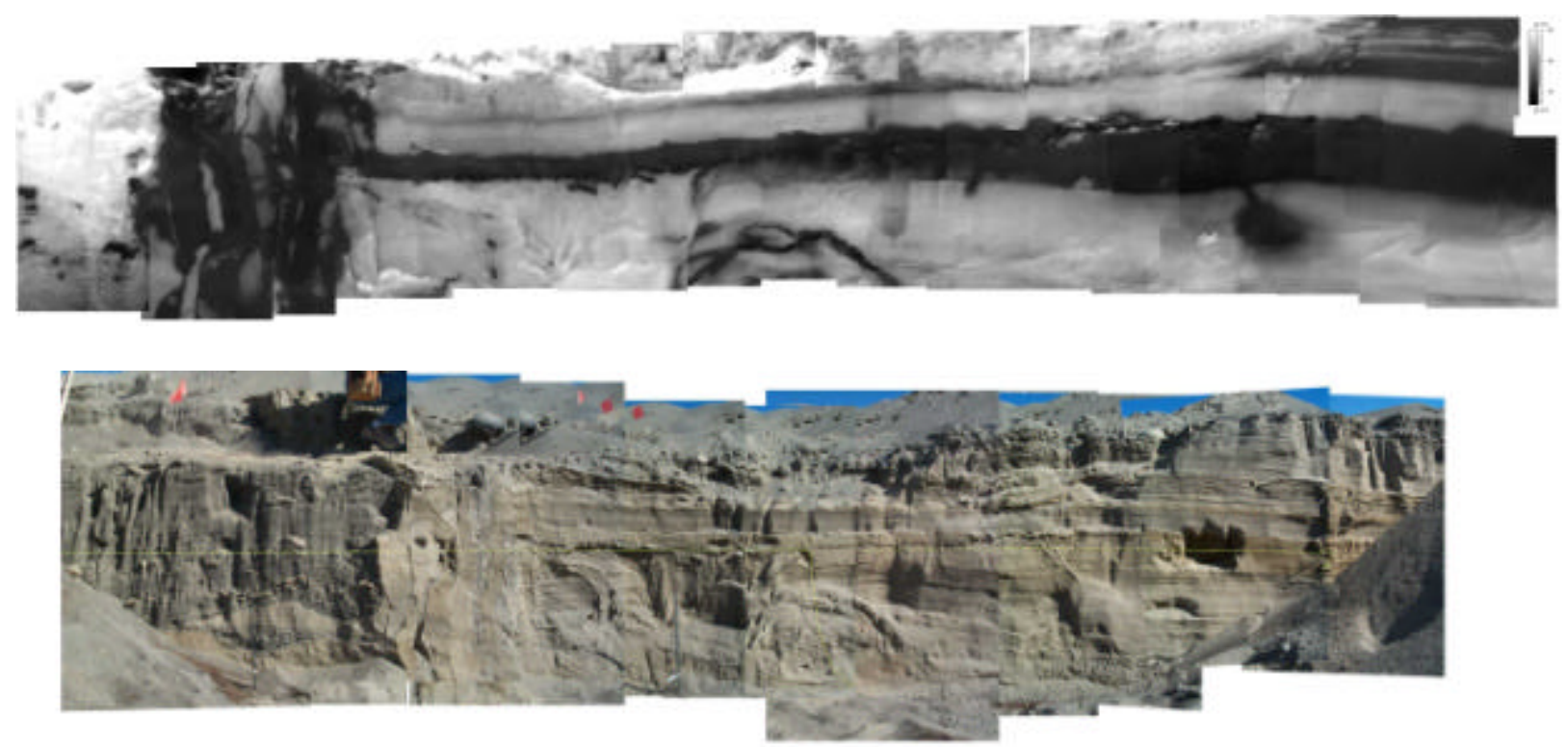

Figure 9. Composite Photographs of the Lower Part of the Trench at the 216-S-Pond. The upper photo is an infrared image and the lower photo is a normal photograph.

is the clastic sill. An attempt will be made to calibrate the infrared data to the air permeability moisture data. Several hundred air permeability measurements were obtained from the exposures in the trench.

Figure 10 shows the distribution of the air permeability results. The dike and sill exposed in the trench tend to be finer-grained than the host material and therefore have a higher moisture content and lower permeability than the host material. Figure 11 shows a box plot comparing the moisture content in the dike and host materials. Moisture content was determined gravimetrically from samples collected at the trench.

We collected samples from the dike and host sediment to compare the mineralogy and grain size distribution between the dike and host sediment. Qualitative X-ray diffraction analysis of 21 samples showed that the mineral composition of both the dike and the host sediment is dominated by quartz and plagioclase feldspar. Lesser amounts of pyroxene, mica, chlorite, and amphibole are also present in most samples. Calcite was identified in only three samples. No apparent differences were found in the mineral composition between the dike and host sediment. We submitted 19 samples for analysis of particle size distribution. In general, the samples from the dike tend to be much finer-grained than are samples of host sediment.

In addition to the above tests, we conducted drip-irrigation and dye-tracer studies at the excavation. Vertical time-domain reflectometry probes, 0.25 meter long, were driven into the exposed horizontal face at 0.15 meter back from the exposed vertical face. These probes were spaced every 0.3 meter along the traverse. Horizontal probes, 0.5 meter long, were driven into the exposed vertical face in a grid with spacings of 0.3 meter horizontally and 0.15 meter 


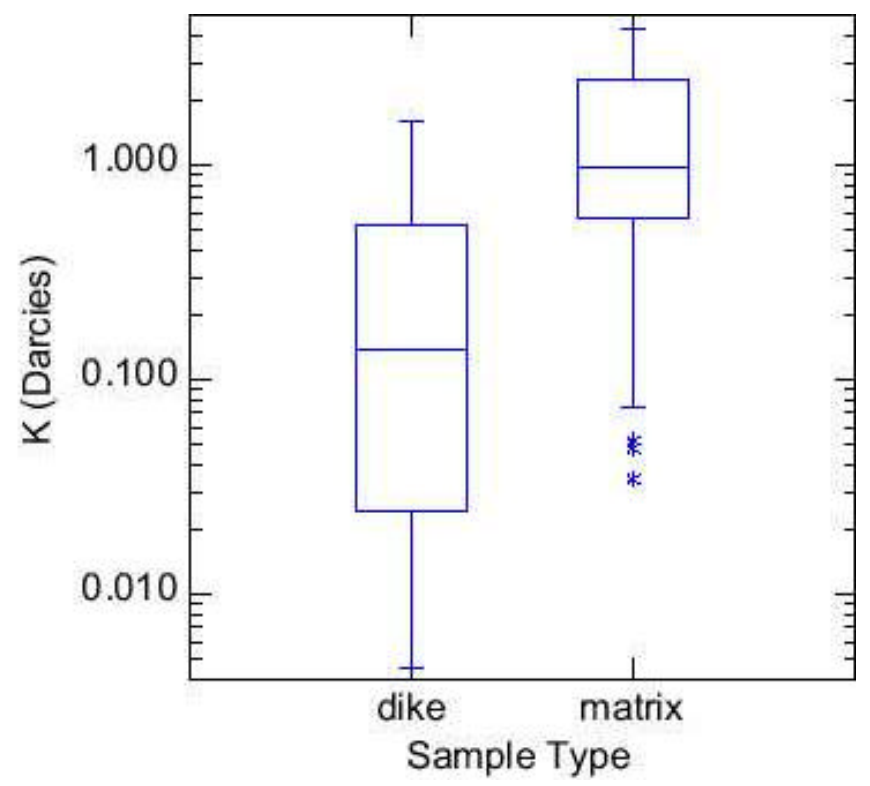

Figure 10. Air Permeability Data from Dike and Host Sediment at 216-S-16 Pond

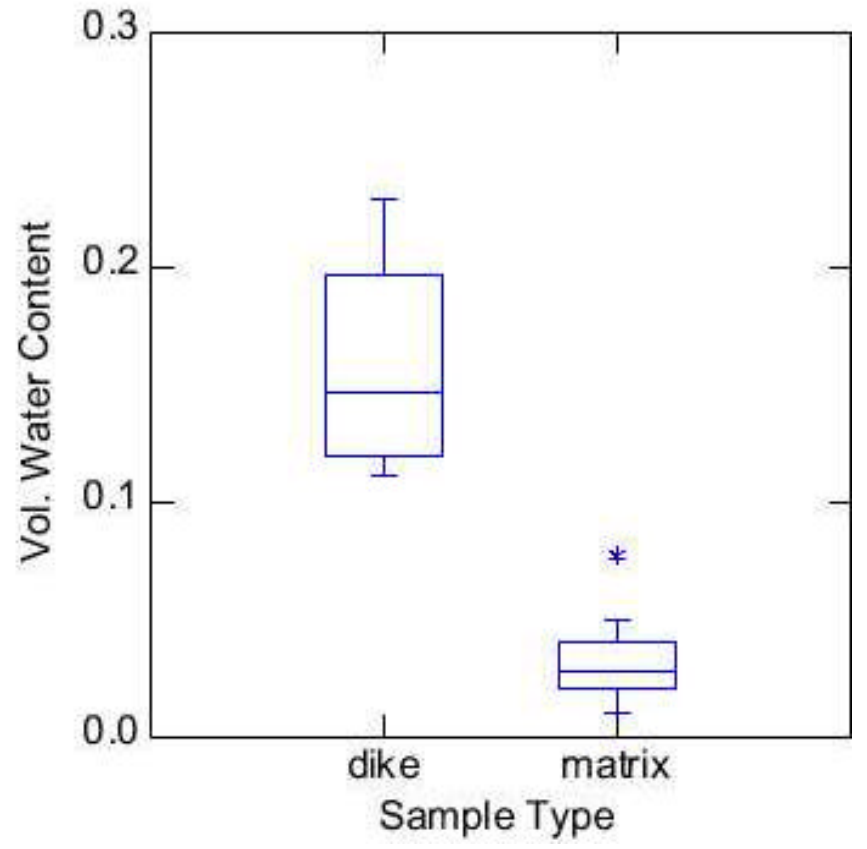

Figure 11. Gravimetric Water Content of Samples Collected from the Dike and Host Sediment at 216-S-Pond 
vertically. A drip irrigation system with lines spaced $\sim 5$ centimeters apart was used to uniformly deliver known amounts of water. We measured several parameters during the experiment. Volumetric water content was monitored along the surface and the cut face. Soil-water pressure head was monitored with tensiometers along the bench surface, and field-saturated conductivity was measured every 0.15 meter along the bench surface using a tension infiltrometer. In addition, we collected soil samples on a 15-by-15 centimeter grid on the cut face to analyze for particle-size distribution.

Five injections of water were applied, totaling 738 liters. Brilliant Blue dye was mixed with the water for the last injection. Figure 12 shows the distribution of soil moisture three days after the first injection. The figure shows that the wetting front appears deeper in the dike than in the relatively coarser-grained host sediment. This is partly due to capillary wicking of the finer sediment in the dike. The water was applied so that the soil remained unsaturated; therefore, capillary wicking was quite important. After nearly a week, the entire exposed face on the west of the dike was visibly wet to a depth of greater than 1 meter, while on the east side the sediment appeared to be uniformly wet to a depth of $\sim 75$ centimeters, or $\sim 20$ centimeters below the bottom of the horizontal clastic sill.

Figure 13 shows the distribution of dye 1 day after injection and 8 days after we initiated prewetting. The dye injection preferentially infiltrates the coarser-grained parts of the dike and the coarse-grained host sediment. The dye trace results suggest that clastic dikes containing fine sediment may actually retard vertical flow rather than act as conduits to fluids applied at the upper surface of the dike. The results also suggest that such features may act as vertical cutoff walls, limiting the horizontal spread of fluids that otherwise could move significant distances laterally in response to large-scale anisotropic features such as graded horizontal layering, which is typical of most Hanford sediment.

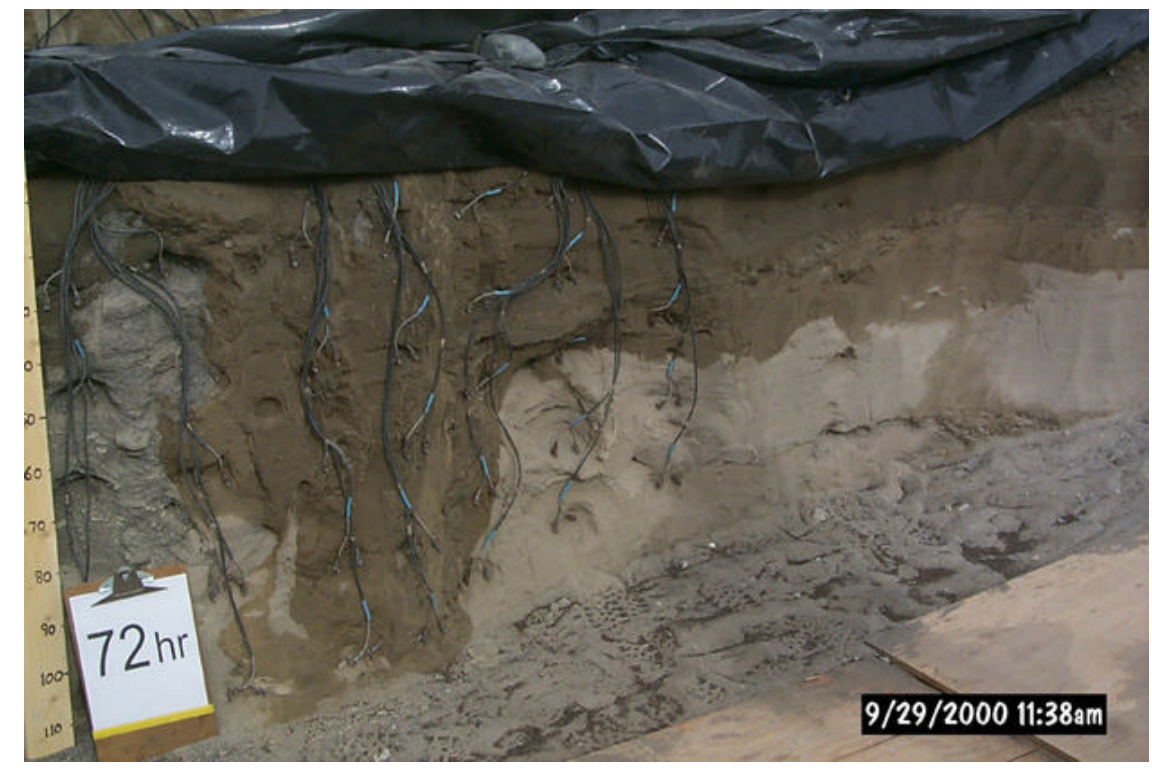

Figure 12. Distribution of Soil Moisture Three Days after the first Injection of Water 


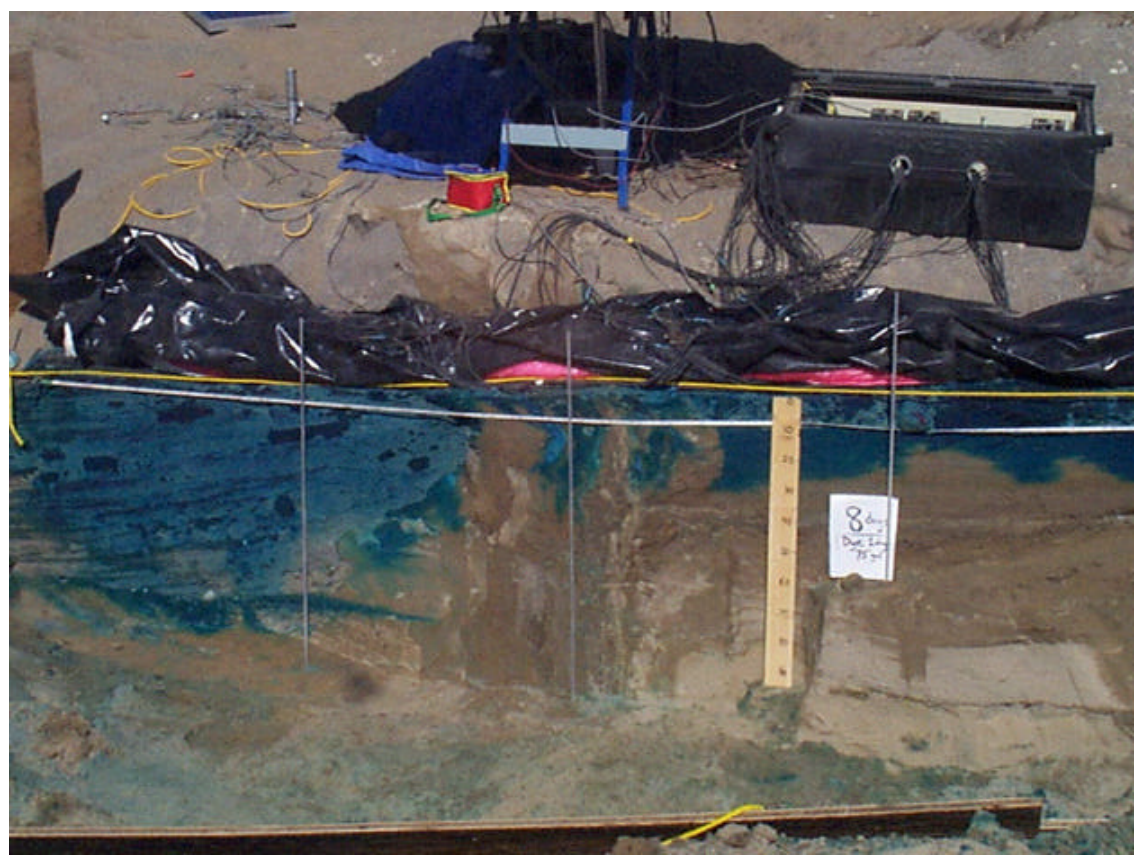

Figure 13. Dye and Water Distribution in Clastic Dike and Adjacent Host Sediment 1 Day after Dye Injection and 8 Days after Prewetting

\section{Planned Activities}

Additional field work will be conducted at the Hanford Site through July of 2001, at the Army Loop Road field location (Figure 1). We are conducting a large-scale infiltration experiment covering an area of about $30 \mathrm{~m}^{2}$ at a site containing a clastic dike. During the infiltration experiment, we will monitor migration of water and tracers in the vadose zone with a suite of advanced and standard geophysical methods (cross borehole radar tomography, time domain reflectometry [TDR], and neutron probes). We will use the data collected from this experiment to derive flow and transport parameters for the dike and surrounding matrix, as well as provide field data with which to perform geostatistical and hydraulic flow modeling. Following the infiltration test, we will characterize the physical and hydraulic properties of the site by excavating the clastic dike adjacent to the infiltration site and conducting in situ tests (e.g., air permeability, visual observation, infrared imaging, tension infiltrometer) and by taking samples for standard laboratory analyses of physical and hydraulic properties. We will use geostatistical methods in late FY 2001 and in FY 2002 to produce numerical three-dimensional grids of the infiltration site for flow and transport modeling of the vadose zone. We will perform flow and transport modeling in FY 2002, and the resulting transport models will be compared with the observations made during the transport experiments. 